\title{
Adverse events following immunization (AEFI) reports of extended program immunization (EPI) in Indonesia during 1998-2002
}

\author{
Nastiti Kaswandani, MD; Sri Rezeki Hadinegoro, MD, PhD; Rulina Suradi, MD
}

\begin{abstract}
Background The incidence of adverse events following immunization (AEFI) increased in correlation with the number of vaccine doses. Meanwhile AEFI reports should be managed properly to maintain the compliance and immunization coverage.

Objectives The aims of this study were to investigate the incidence and profile of AEFI, its onset, severity, classification, and outcome.

Methods This study was a passive surveillance of $A E F I$ reports received by the National Committee on AEFI, Ministry of Health of Indonesia, during 1998 to 2002.

Results Two hundreds and four AEFI cases were reported; 4 cases as zero reports, 182 cases as individual reports, and 18 cluster reports. The AEFI incidence was 0.44 per 1 million doses of vaccines. Vaccine reaction rate was 1 per 2.3 million vaccine doses. The most common vaccines reported as the causes of AEFI were DTP, Polio, and TT. Among 182 reported cases, local or mild AEFI reactions were observed in 45 , moderate in 49 , and severe in 88 . Based on WHO field classification, this study reported that 84 cases belonged to coincidence, 72 to vaccine reactions, 13 to programmatic errors, 7 to injection reactions, and 6 to unclassified reactions. Forty-seven patients died, 12 had some sequelae, and 123 completely recovered. Meanwhile, among the death cases, $70 \%$ occurred coincidently, $17 \%$ due to vaccine reactions, and 6 were unclassified.

Conclusions The incidence of AEFI in the extended program immunization (EPI) in Indonesia during the period of 1998-2002 were 182 cases, thus vaccine reaction rate was 1 per 2.3 million vaccine doses. The most common vaccine which caused AEFI was DTP. Most AEFI with severe symptoms happened in 4-24 hours after immunization. [Paediatr Indones 2004;44:153-159].
\end{abstract}

Keywords: immunization, adverse events following immunization, extended program of immunization, vaccine reaction.

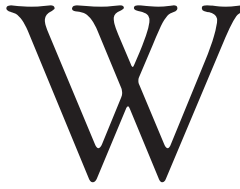

orld Health Organization reported that every year, 2 millions of children died because of vaccine-preventable diseases. ${ }^{1}$ The effectiveness of immunization in preventing infectious disease had been proven. ${ }^{2-5}$ Chen stated that the incidence of adverse events following immunization (AEFI) increased in accordance with the increasing amount of immunized children. ${ }^{6}$ Concerning that event, the Institute of Medicine in USA (IOM, 1994) defined AEFI as an event affecting negatively the individual's health after receiving vaccine. ${ }^{7}$ It is extremely difficult to determine whether AEFI is due to the vaccine reaction or as a coincidence with other diseases. ${ }^{8}$ Any AEFI report should be managed properly to reduce drop out and to maintain the immunization coverage as the risks of nature infection are much greater than the risks of vaccination. ${ }^{9-11}$

To manage and control AEFI in Indonesia, the Ministry of Health has established The National Committee on AEFI that consisted of clinicians, profes-

From the Department of Child Health, Medical School, University of Indonesia, Cipto Mangunkusumo Hospital, Jakarta.

Reprint requests to: Nastiti Kaswandani, MD, Department of Child Health, Medical School, University of Indonesia, Cipto Mangunkusumo Hospital, Jakarta, Indonesia. Tel. 62-21-3907740, Fax. 62-21-3907743, email: nkaswandani@yahoo.com. 
sional organizations, and experts in the field of microbiology, virology, vaccine, pharmacology, epidemiology, and medico legal aspects. The National Committee on AEFI received AEFI reports from all health centers via health offices in district level from all provinces in Indonesia and audited those reports. The aims of this study were to investigate the incidence and profile of AEFI cases, its onset and severity, also its classification and outcome.

\section{Methods}

This was a descriptive study on all AEFI reports received by the AEFI National Committee, Ministry of Health of Indonesia during 1998-2002; data were taken by passive surveillance. Data of patients' identification (name, age, and gender), symptoms and onset of AEFI, severity, and outcomes of AEFI were collected from AEFI form-sheets. The National Committee audited all the AEFI reports by using field classifications as well as causality classification. Vaccine reaction rate was calculated based on the ratio between the number of reported AEFI cases and the number of vaccine doses that had been used in the certain period of time.

Adverse event following immunization was defined as a medical incidence occurring after immunization, which was believed was caused by immunization. $7,9,11-12$ The Indonesian National Committee on AEFI limited AEFI in the period of one month after an immunization. ${ }^{13}$ Local reactions such as swelling, pain, and redness on the site of injection were categorized as mild reactions, ${ }^{11}$ while fever, malaise, lymphadenitis, headache, or urticaria as moderate reactions; and neurological symptoms such as convulsion, unconsciousness, paralysis, hypotonic hyporesponsive episode, anaphylactic shock, or any AEFI that needs hospitalization or causes death as severe reactions. ${ }^{11,13-16}$ Classification of AEFI was determined according to the National Committee of AEFI. ${ }^{13}$ Causality classification consisted of causality 1 (no evidence was available to establish a causal relationship), causality 2 (inadequate evidence to accept or reject a causal relationship), causality 3 (evidence favored rejection of a causal relationship), causality 4 (evidence favored acceptance of a causal relationship), and causality 5 (evidence established a causal relationship), 3,6 while the field classification of WHO consisted of programmatic error (AEFI caused by error in vaccine preparation, handling, or administration), injection reaction (AEFI caused by anxiety or pain of injection), vaccine reaction (AEFI caused by vaccine's inherent properties), coincidental (AEFI happens after immunization but not caused by it), and unknown (cause cannot be determined). ${ }^{11}$

Data collected were processed using computer program of EPI INFO 2002.

\section{Results}

During the period of 1998-2002, the Indonesian National Committee of AEFI received 204 AEFI reports. The reports consisted of three types of reports i.e., 4 zero reports, 182 individual case reports, and 18 cluster reports. Data came from 11 out of 27 provinces during 1998, followed by 7 of 27, 13 of 29, 9 of 30, and 14 of 31 provinces during 1999, 2000,

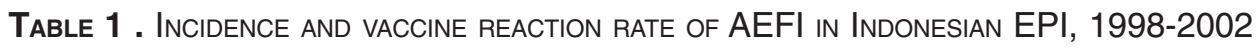

\begin{tabular}{|c|c|c|c|c|c|c|c|c|}
\hline \multirow[t]{2}{*}{ Vaccines } & \multicolumn{5}{|c|}{ Cases per year } & \multirow{2}{*}{$\begin{array}{l}\text { Total } \\
\text { n (\%) }\end{array}$} & \multirow{2}{*}{$\begin{array}{l}\text { Doses of } \\
\text { vaccines } \\
\text { (million) }\end{array}$} & \multirow{2}{*}{$\begin{array}{l}\text { Vaccine } \\
\text { reaction rate } \\
(1 / \mathrm{million})\end{array}$} \\
\hline & 1998 & 1999 & 2000 & 2001 & 2002 & & & \\
\hline $\mathrm{BCG}$ & 1 & 2 & 1 & 2 & 2 & $8(4.4)$ & 22.7 & $1: 2.8$ \\
\hline Polio & 11 & 1 & 1 & 0 & 26 & $39(21.4)$ & 86.97 & $1: 2.2$ \\
\hline Hepatitis B & 1 & 3 & 4 & 8 & 7 & 23 (12.6) & 53.87 & $1: 2.3$ \\
\hline DTP & 11 & 7 & 19 & 6 & 13 & $56(30.8)$ & 65.52 & $1: 1.2$ \\
\hline DT & 2 & 2 & 0 & 3 & 1 & $8(4.4)$ & 24.79 & $1: 3$ \\
\hline TT BIAS ${ }^{\star}$ & 5 & 12 & 5 & 5 & 0 & $27(14.8)$ & 106.58 & $1: 3.9$ \\
\hline TT WUS ${ }^{\star *}$ & 0 & 3 & 2 & 0 & 0 & $5(2.7)$ & 32.92 & $1: 6.6$ \\
\hline Measles & 1 & 1 & 13 & 1 & 0 & $16(8.8)$ & 1.09 & $1: 1.3$ \\
\hline Total & 32 & 31 & 45 & 25 & 49 & $182(100)$ & 414.42 & $1: 2.3$ \\
\hline
\end{tabular}

* BIAS ( bulan imunisasi anak sekolah) = school children immunization program

** WUS (wanita usia subur) = women in childbearing age group 
Nastiti Kaswandani et al: Adverse events following immunization in extended program in Indonesia

Table 2. Onset, SEVerity, AND OUtcomes of AEFI In Indonesian EPI 1998-2002

\begin{tabular}{|c|c|c|c|c|c|c|}
\hline & \multicolumn{4}{|c|}{ Cases per year } & & \multirow[t]{2}{*}{ Total n (\%) } \\
\hline & 1998 & 1999 & 2000 & 2001 & 2002 & \\
\hline \multicolumn{7}{|l|}{ Onset. } \\
\hline$\leq 4$ hours & 5 & 9 & 15 & 11 & 11 & $51(28.0)$ \\
\hline$>4-24$ hours & 4 & 12 & 11 & 8 & 24 & 59 (32.4) \\
\hline >24-72 hours & 4 & 9 & 7 & 5 & 9 & 34 (18.7) \\
\hline$>3-30$ days & 17 & 1 & 11 & 1 & 2 & $32(17.6)$ \\
\hline$>30$ days & 2 & 0 & 1 & 0 & 3 & $6(3.3)$ \\
\hline Total & 32 & 31 & 45 & 25 & 49 & $182(100)$ \\
\hline \multicolumn{7}{|l|}{ Severity } \\
\hline . $\quad$ Mild & 11 & 10 & 16 & 5 & 3 & $45(24.7)$ \\
\hline Moderate & 3 & 14 & 9 & 8 & 15 & 49 (26.9) \\
\hline Severe & 18 & 7 & 20 & 12 & 31 & $88(48.4)$ \\
\hline Total & 32 & 31 & 45 & 25 & 49 & $182(100)$ \\
\hline \multicolumn{7}{|l|}{ Outcomes } \\
\hline Recovered & 25 & 25 & 30 & 17 & 26 & $123(67.6)$ \\
\hline Sequelae & 2 & 1 & 3 & 1 & 5 & $12(6.6)$ \\
\hline Died & 5 & 5 & 12 & 7 & 18 & 47 (25.8) \\
\hline Total & 32 & 31 & 45 & 25 & 49 & $182(100)$ \\
\hline
\end{tabular}

Table 3. Classification of AEFI In Indonesian EPI 1998-2002

\begin{tabular}{|c|c|c|c|c|c|c|}
\hline \multirow[t]{2}{*}{ Classification } & \multirow[b]{2}{*}{1998} & \multicolumn{3}{|c|}{ Cases per year } & \multirow{2}{*}{\multicolumn{2}{|c|}{$\begin{array}{c}\text { Total } \\
\mathbf{n}(\%) \\
\end{array}$}} \\
\hline & & 1999 & 2000 & 2001 & & \\
\hline \multicolumn{7}{|l|}{ Field classification } \\
\hline Programmatic error & 0 & 0 & 0 & 4 & 9 & $13(8.6)$ \\
\hline Injection reactin & 0 & 3 & 2 & 2 & 0 & $7(3.8)$ \\
\hline Vaccine reaction & 17 & 18 & 28 & 7 & 2 & $72(39.6)$ \\
\hline Coincidence & 14 & 10 & 15 & 10 & 35 & $84(46.2)$ \\
\hline Total & 0 & 0 & 0 & 0 & 0 & 0 \\
\hline Unknown & 1 & 0 & 0 & 2 & 3 & $6(3.3)$ \\
\hline Unclassified & 32 & 31 & 45 & 45 & 49 & $182(100)$ \\
\hline \multicolumn{7}{|c|}{ Causality classification } \\
\hline Causality 1 & 0 & 0 & 5 & 13 & 8 & $26(14.3)$ \\
\hline Causality 2 & 0 & 0 & 4 & 0 & 2 & $6(3.3)$ \\
\hline Causality 3 & 13 & 10 & 8 & 2 & 34 & $67(36.8)$ \\
\hline Causality 4 & 18 & 21 & 26 & 8 & 2 & 75 (41.2) \\
\hline Causality 5 & 0 & 0 & 2 & 0 & 0 & $2(1.1)$ \\
\hline Unclassified & 1 & 0 & 0 & 2 & 3 & 6 (3.3) \\
\hline Total & 32 & 31 & 45 & 25 & 49 & $182(100)$ \\
\hline
\end{tabular}

2001, and 2002 respectively. Among these reports, 182 individual AEFI case reports had complete data to be analyzed. The incidences of AEFI were 32, 31, 45, 25 , and 49 in the year of 1998, 1999, 2000, 2001, and 2002 respectively. The overall AEFI incidence was 0.44 per 1 million doses of vaccines. Vaccine reaction rate among all vaccine was 1 per 2.3 million doses (182 reported data among 414.42 million vaccine doses). AEFI of DTP, polio, TT BIAS (TT at school children immunization program), hepatitis B, measles, BCG, DT, and TT WUS (TT at the childbearing women group) vaccines were $56,39,27,23,16,8,8$, and 5 cases respectively (Table 1 ).
The most affected children were boys (56.6\%), occurring mostly in the first year of age (57.7\%), while in above five year-old was $26.9 \%$. Table 2 shows the proportion of onset, severity, and outcome of AEFI. The most common AEFI occurred during 4 to 24 hours after immunization. Symptoms of AEFI were dominated by severe symptoms. But fortunately, most AEFI recovered completely. Based on WHO field of classification, coincidence (84 cases) and vaccine reactions (72 cases) were the most common causes of AEFI in Indonesian EPI.

The most common reaction of DTP vaccines was mild symptom (injection site reactions), while Polio 
vaccination had severe symptoms such as paralysis. Severe vaccine-related AEFI were found, like 4 cases of anaphylactic shock due to DTP, Hepatitis B, and TT; 5 cases with inconsolable crying, 5 with convulsions, 5 with encephalopathy, and 3 with HHE caused by DTP vaccination. Other severe reactions were not related to vaccination but due to other diseases (coincidence).

Among 47 deaths in this study, more than 70\% were categorized as coincidence, while 8 were due to vaccine reactions. Some coincidental diseases correlated with AEFI were pneumonia, encephalitis, sepsis, prematurity, severe malnutrition, and gastroenteritis dehydration. Six AEFI cases could not be classified due to insufficient data. Twelve patients had some sequelae such as paralysis, involuntary movement, skin lesions, and tissue scarring caused by an aseptic incision of cold abscess at the local site of vaccine injection.

Figure 1 shows that severe AEFI mostly occurred in the first twenty-four hours after immunization, meanwhile the majority of mild AEFI occurred after 3 days of immunization.

During the period of 1998 to 2002, there were 18 cluster AEFI cases reported from different parts of this country to the National Committee. Unfortunately, the National Committee of AEFI had not analyzed the cluster AEFI yet. All clusters of AEFI reports showed mild cases, which completely recovered and did not need hospitalization.

\section{Discussion}

Post marketing (passive) surveillance was conducted in this study, so that data collection was less complete than actual AEFI data reported by active surveillance. Vaccine reaction rate was 0.44 per million doses of vaccines. This finding was extremely low compared to WHO estimation, ${ }^{17}$ 40-100 per I million doses, or to Australian ${ }^{18}$ and USA ${ }^{19}$ data, 45 per million doses in 2000-2002 and 114 per million doses in 1991-2001, respectively.

Some experts stated that the number of AEFI cases was lower than expected due to poor knowledge and attitude of health providers to report the AEFI, underreporting of mild reaction of AEFI, unwillingness of health providers to report because they thought they would be considered incompetent doing their job, and lack of parents' participation in AEFI reporting. ${ }^{5,9,11}$ Almost all severe AEFI were reported while the mild and moderate ones were not. Parents did not report any mild reaction such as low degree of fever and pain or swelling on the injection site. The consequence is that the number of severe AEFI cases were much higher than mild AEFI. ${ }^{17}$ In the future, if health providers have more concern in AEFI reporting and parents' participation increase, the number of mild AEFI will increase like those reported in Australia and USA.

Pertussis component of the DTP vaccine is the most common cause of the adverse event as reported

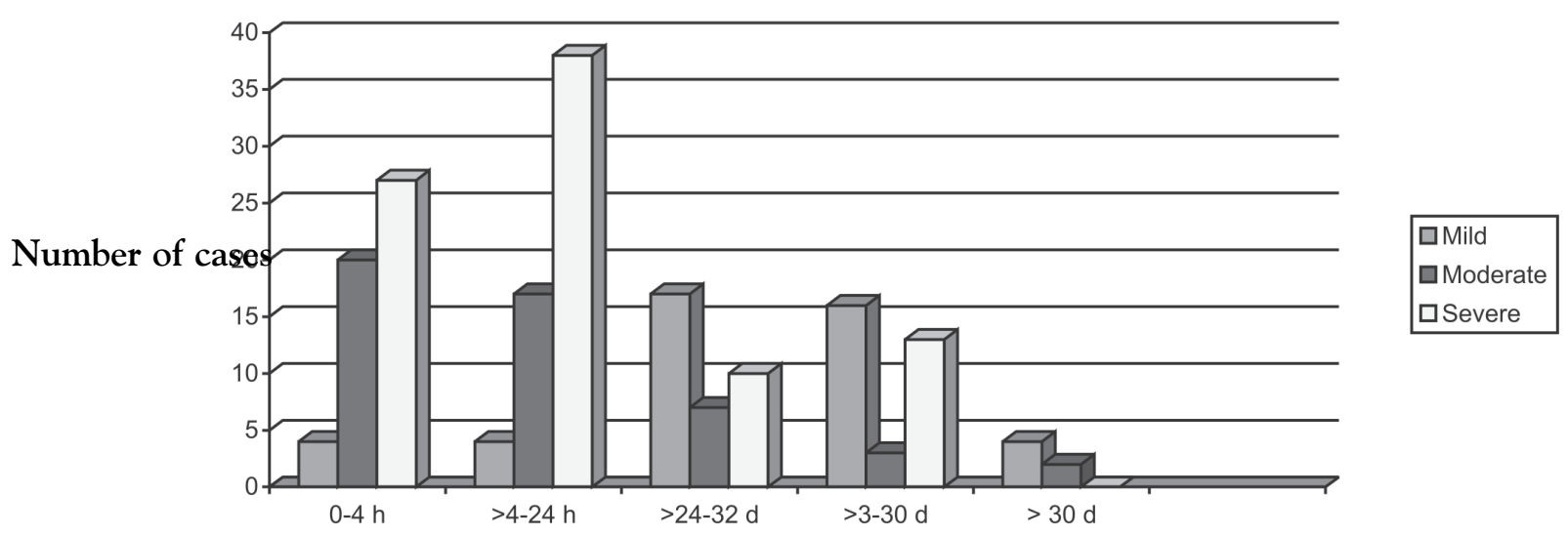

Figure 1. Interval and severity of AEFI 


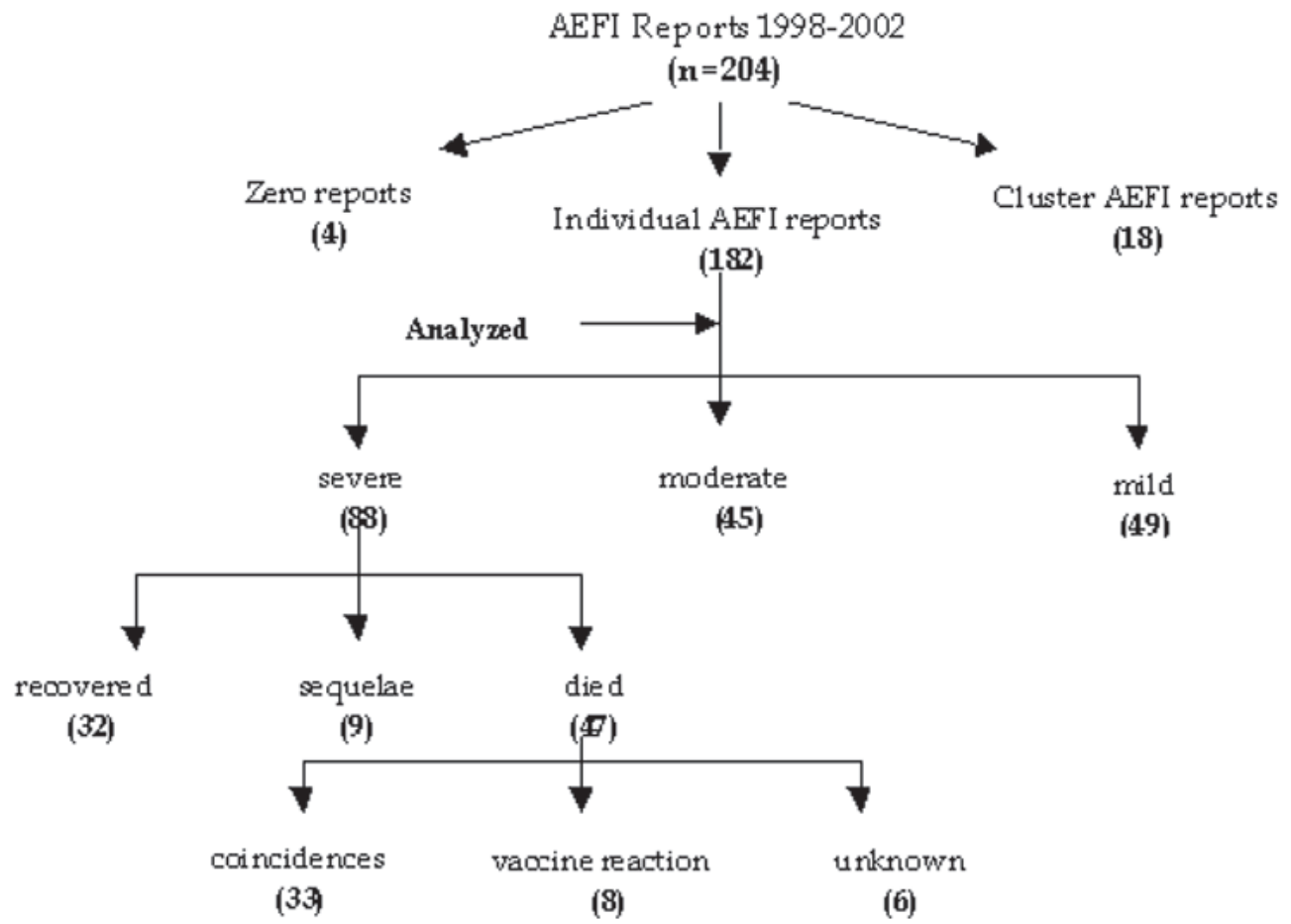

by many authors. ${ }^{6,10-11}$ Other vaccines reported were polio and measles. Polio vaccines were given in a big volume during the national immunization days in 1998 and 2002, while measles vaccine was given at the school immunization program in 2000. The severe vaccine reaction that could occur after OPV (Oral Polio Vaccine) vaccination is vaccine-associated paralytic polio (VAPP). VAPP is an acute flaccid paralysis that occurs during 4-30 days after receiving OPV vaccination or during 4-75 days after contact with a recipient of OPV and with neurological deficits remaining for 60 days after onset, or death. This study found that no AEFI after OPV showed paralysis symptoms proven as VAPP. It was similar to what WHO had analyzed that there had been no increase in the rate of VAPP during campaigns. ${ }^{11}$

In planning for the OPV cessation era, a major concern is the possibility of vaccine-derived polioviruses (VDPV) acquiring the wild poliovirus-like property of sustained circulation in a population. VDPV are field isolates consistent with an extensive period of virus excretion or transmission in the community, usually demonstrating 1-15\% differences from parent OPV strains by full virus Polio-1 sequence homology. Genomic sequencing of Sabin polioviruses isolated from Egypt in 1983-1992 and Haiti/Dominican Republic in 2000-2001 had confirmed that sustained circulation of virulent VDPV could occur. So far sustained circulation of VDPV had been identified by serendipity on just these occasions i.e., in populations where immunity was low. It is essential to undertake systematic searches to determine the frequency of sustained VDPV circulation. ${ }^{20}$

No serious adverse events of measles vaccination in school immunization program were found. Most adverse events that occurred during vaccination campaign were the results of unsafe injection, unqualified volunteer, and more public concern to any adverse events occurring to their children. ${ }^{21}$

Mild AEFI reactions after DTP or other vaccine were local reactions such as redness, swelling, and pain on the injection site. Local reactions occurred because DTP vaccines were not injected intramuscularly or in deep subcutaneous. This will induce delayed hypersensitivity reactions to the diphtheria proteins. The other reason was unsafe injection that caused infection in the injection site. WHO reported that more than $50 \%$ unsafe injection had been given to children in developing countries. A study by Kosen found that there were $2.5-37.5 \%$ unsafe injections in Indo- 
nesia. ${ }^{22}$ South Australian Immunisation Coordination Unit (SAICU) reported 104 injection adverse reactions out of 263 AEFI with the risk of unsafe injection of 1 reaction per 165 injections. ${ }^{23}$

We found some diseases such as pneumonia, encephalitis, and sepsis, reported coincidently with the adverse events of some vaccines. Young babies who suffer from severe infections have no significant apparent symptoms, as in older babies. Thus, there was a big possibility that non-doctor health providers did not detect the symptoms. Increased knowledge and skill of non-doctor health providers, especially young midwives, to diagnose the severe degree of common infectious diseases in a baby is necessary.

Vaccine reactions can be mild or severe in clinical manifestations. In mild AEFI, no medical treatment is required. On the contrary, special treatment is necessary for severe reactions such as inconsolable crying, convulsions, or suppurative lymphadenitis. Fatal condition including encephalopathy and anaphylactic shock should be differentiated with other similar conditions such as syncope, hypotensive hyporesponsive episode, anxiety episode, or breath holding spells, which have better prognosis. Early AEFI in this study mostly occurred as severe symptoms. It is important to pediatricians or other health providers to observe immunized children for several minutes to anticipate early severe reactions.

This study found 18 cluster AEFI reports, unfortunately without further investigations. A cluster is two or more cases of same adverse events related in time, time interval since vaccination, geography, or vaccine administered. ${ }^{20}$ Ideally, every cluster of AEFI report should be investigated and analyzed to determine the definitive cause of the cluster. Programmatic errors in vaccine cold chain, injection technique, vaccine sterility ,or indication and contraindication in giving vaccine could make a cluster of AEFI. If the symptoms of AEFI also occurred in non-immunized children, the cluster may be a coincidence. ${ }^{11}$ The vaccine reactions of the AEFI cluster in this study were mild and completely recovered without hospitalization.

As a conclusion, the number of AEFI reports received by the Indonesian National Committee of AEFI was still less than expected. The incidence of AEFI during 1998-2002 was 182 cases. Vaccine reaction rate was 1 per 2.3 million doses of vaccines. The most common vaccine causing AEFI was DTP. Most
AEFI with severe symptoms happened in 4-24 hours after immunization. To increase the quantity and quality of AEFI reports, the health providers' knowledge and attitude towards AEFI and also parents' participation in reporting AEFI should be improved.

\section{References}

1. World Health Organization. The world report 1998. Geneva: WHO; 1998. p. 62.

2. The National Vaccine Advisory Committee. Strategies to sustain success in childhood immunizations. JAMA 1999; 282:363-9.

3. National Health and Medical Research Council. The Australian immunisation handbook. 6th ed. Canberra: NHMRC; 1997. p. 1-17.

4. Hadinegoro SR. Imunisasi pada anak: state of the art. Presented at Kongres PETRI V; 1999 Nov 19-21; Makassar.

5. Ward BJ. Vaccine adverse events in the new millennium: is there reason for concern? Bull World Health Organ 2000;78:205-15.

6. Chen RT. Safety of vaccines. In: Plotkin SA, Orenstein WA, editors. Vaccines. 3rd ed. Philadelphia: WB Saunders; 1999. p. 1144-63.

7. Stratton KR, Howe CJ, Johnston RB. Adverse events associated with childhood vaccines. Washington DC: Institute of Medicine; 1994. p. 1-55.

8. Loupi E, Baudard S, Debois H, Pignato F. Risk associated with vaccinations. Ann Med Interne 1998;149:361-71.

9. Mehta U, Milstien JB, Duclos P, Folb PI. Developing a national system for dealing with adverse events following immunization. Bull World Health Organ 2000;78:170-7.

10. Atkinson W, Wolfe C, Humiston S, Nelson R. Epidemiology and prevention of vaccine-preventable diseases. 6th ed. Georgia: Public Health Foundation; 2000. p. 144-63.

11. World Health Organization. Immunization safety surveillance. Geneva: WHO; 1999. p. 9-38.

12. Hadinegoro SR. Kejadian ikutan pasca imunisasi. Sari Pediatri 2000;2:2-10.

13. Komite Nasional Pengkajian \& Penanggulangan Kejadian Ikutan Pasca Imunisasi (KN-PP KIPI). Pedoman tatalaksana medik kejadian ikutan pasca imunisasi (KIPI) bagi petugas kesehatan. 4th ed. 
Jakarta: Direktorat Jenderal PPM-PL Departemen Kesehatan RI; 2002.

14. Chen RT, Glasser JW, Rhodes PH. Vaccine safety datalink project: a new tool for improving vaccine safety monitoring in the United States. Pediatrics 1997;99:765-73.

15. Du Vernoy TS, Braun MM. Hypotonic-hyporesponsive episodes reported to the Vaccine Adverse Event Reporting System (VAERS), 1996-1998. Pediatrics 2000;106:E52.

16. Singleton JA, Lloyd JC. Mootrey GT, Salive ME, Chen RT. An overview of the vaccine adverse reporting system (VAERS) as a surveillance system. Vaccine 1999;17:2908-17.

17. WHO. Supplementary information on vaccine safety part 2: background rates of adverse events following immunization. Geneva: WHO; 2000. p. 1-5.

18. Lawrence G, Menzies R, Burgess M, McIntyre P, Wood $\mathrm{N}$, Boyd I, et al. Surveillance of adverse events following immunisation: Australia, 2000-2002. Commun Dis Intell 2003;27:307-23.

19. Zhou W, Pool V, Iskander JK, English-Bullard R, Ball R, Wise RP, et al. Surveillance for safety after immunization: vaccine adverse event reporting system (VAERS) United States, 1991-2001. MMWR 2003;52:1-13.

20. WHO. Supplementary information on vaccine safety part 1: field issues. Geneva: WHO; 2000. p. 3-9.

21. WHO. Global action plan for laboratory containment of wild polioviruses. 2nd ed. Geneva: WHO; p. 4-6.

22. Kosen S. Study on safe injection practice in immunization campaign for schoolchildren (BIAS). A report prepared for the Sub Directorate of Epidemiology and Immunization, Directorate General of CDC and AHG, $\mathrm{MOH}$. Rep of Indonesia and the World Health Organization; 1999.

23. SAICU. Vaccine safety reports from 1 January to 30 June 2002. Bulletin CDC 2002;11:1-8. 